\title{
Experimental Oronasal Transmission of Chronic Wasting Disease Agent from White-Tailed Deer to Suffolk Sheep
}

\author{
Eric D. Cassmann, S. Jo Moore, Justin J. Greenlee
}

Chronic wasting disease (CWD) is a fatal prion disease of cervids. We examined host range of CWD by oronasally inoculating Suffolk sheep with brain homogenate from a CWD-positive white-tailed deer. Sixty months after inoculation, 1/7 sheep had immunoreactivity against the misfolded form of prion protein in lymphoid tissue. Results were confirmed by mouse bioassay.

Transmissible spongiform encephalopathies (TSEs), also known as prion diseases, are a group of fatal neurologic diseases caused by a misfolded form of the prion protein $\left(\mathrm{PrPs}^{\mathrm{Sc}}\right)$. Several TSEs affect livestock, including scrapie in sheep and chronic wasting disease (CWD) in cervids.

Susceptibility of sheep to the agent of scrapie is determined by the host prion protein genotype. Three polymorphisms at codons 136, 154, and 171 of the prion protein gene occur in sheep. The haplotype $A_{136} R_{154} R_{171}$ is associated with resistance to scrapie, whereas VRQ is linked with susceptibility. Likewise, the deer prion protein genotype $\mathrm{GG}_{96}$ is overrepresented in cases of CWD.

CWD was identified in captive mule deer in Colorado, USA, in 1967 (1). Since then, CWD has been reported in $\geq 24$ states in the United States, 2 provinces in Canada, and South Korea (2,3). During 2016, CWD was reported in Europe, and it has since been detected in 3 Nordic countries (Norway, Sweden, and Finland), although CWD strains in Europe were recently shown to be distinct from strains in North America (4). Because of human consumption of cervid meat products and intermingling of various livestock species with wild cervid populations, there is major interest in characterizing the possible host range of CWD.

Scrapie has been implicated as the possible source of CWD in cervids (5). This finding is supported by in

Author affiliation: US Department of Agriculture, Ames, lowa, USA

DOI: https://doi.org/10.3201/eid2712.204978 vitro conversion of sheep prion protein by infectious CWD prions (6) and glycoprofile similarities between scrapie and CWD prions (7). Another similarity between scrapie and CWD is prominent lymphoid accumulation of $\mathrm{PrP}^{\mathrm{Sc}}$ in both species affected (5). Experimental transmission of mule deer CWD to Suffolk sheep by intracranial inoculation, a highly artificial route of transmission, has been performed (8). Widespread peripheral lymphoid accumulation of $\mathrm{PrP}^{\mathrm{Sc}}$ is retained in intracranially CWD inoculated sheep.

The objective of this study was to test the oronasal susceptibility of sheep to the agent of CWD. We report the preliminary findings of an ongoing multiyear study.

\section{The Study}

Initially, we oronasally inoculated (9) seven Suffolk lambs (3-4 months of age) with the $\mathrm{V}_{136} \mathrm{R}_{154} \mathrm{Q}_{171} / \mathrm{ARQ}$ $(\mathrm{n}=2)$, ARQ/ARQ $(\mathrm{n}=4)$, or ARQ/ARR $(\mathrm{n}=1)$ prion protein genotype and $0.1 \mathrm{~g}$ of $10 \%$ (wt/vol) brain homogenate from a $\mathrm{GG}_{96}$ white-tailed deer that had CWD. The sheep were housed indoors in a Biosafety Level 2 agriculture facility separate from scrapie-affected sheep. At 60 months postinoculation, the initial experimental endpoint, sheep were asymptomatic, and all 7 sheep were culled.

We performed a postmortem examination on each sheep and collected a full spectrum of tissues, which we froze and stored in 10\% neutral-buffered formalin. To evaluate lymphoinvasion and neuroinvasion, we tested tissues from the brainstem at the obex and pons, third eyelid, palatine tonsil, lymph nodes (mesenteric and retropharyngeal), spleen, and ileum. We processed the formalin-fixed tissues, embedded in paraffin, and sectioned at optimal thickness (brain, $4 \mu \mathrm{m}$; lymphoid, $3 \mu \mathrm{m}$; and other tissues, $5 \mu \mathrm{m}$ ) for subsequent staining with hematoxylin and eosin and immunohistochemical (IHC) analysis. We used a 

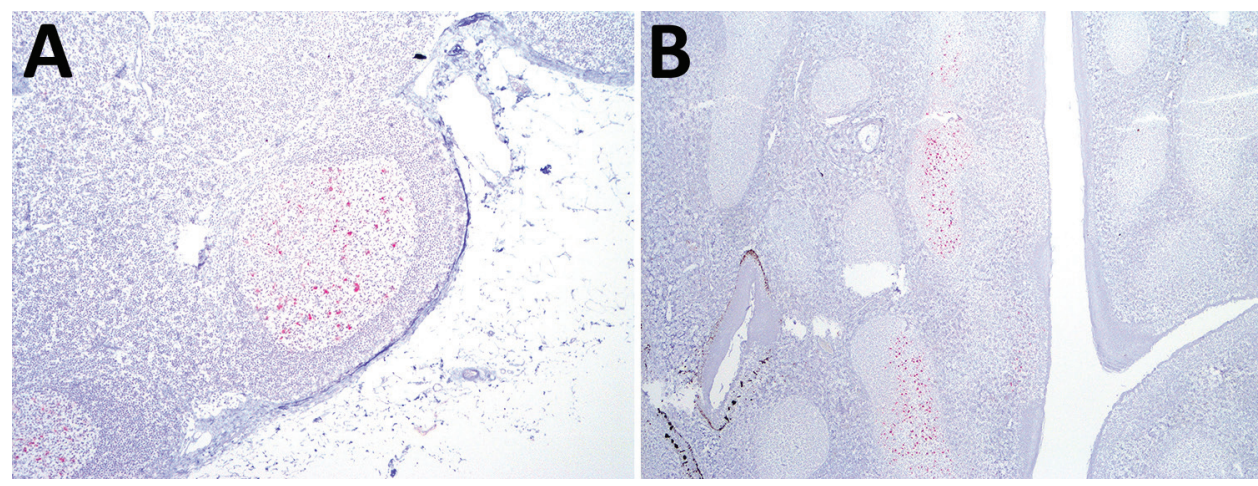

Figure 1. Immunoreactivity against misfolded form of the prion protein (red) in lymphoid tissue from a sheep oronasally inoculated with the agent of chronic wasting disease from white-tailed deer. A) Retropharyngeal lymph node (original magnification $\times 100$.) B) Palatine tonsil (original magnification $\times 40)$. We used a cocktail of monoclonal antibodies (F89/160.1.5 and F99/97.6.1).

cocktail of PrPsc monoclonal antibodies (F89/160.1.5 and F99/97.6.1; $5 \mu \mathrm{g} / \mathrm{mL}$ ) for IHC.

Examination of IHC-stained tissues showed PrPsc in the retropharyngeal lymph node (Figure 1, panel A) and palatine tonsil (Figure 1, panel B) of 1 sheep inoculated with the ARQ/ARQ genotype. The retropharyngeal lymph node was also positive by enzyme immunoassay (EIA) (HerdChek; IDEXX Laboratories, https://www.idexx.com) at initial (optical density 0.99; negative cutoff value 0.186) and repeat (optical density 0.559; negative cutoff value 0.178 ) tests. The palatine tonsil was negative by EIA.

To confirm prion disease infectivity in the retropharyngeal lymph node, we performed bioassays in Tg12 cervidized (10) and Tg338 ovinized (11) transgenic mice. Mice expressed the transgene for the elk prion protein polymorphism $\mathrm{MM}_{132}$ (Tg12) and the ovine prion protein polymorphisms $\mathrm{V}_{136} \mathrm{R}_{154} \mathrm{Q}_{171}$ (Tg338). We homogenized fresh frozen lymph nodes to $10 \%$ (wt/ vol) and enriched them by repeated rounds of differential centrifugation; we intracranially inoculated mice with $20 \mu \mathrm{L}$ of $10 \%$ (wt/vol) equivalent enriched homogenate. The Tg12 bioassay had a partial attack rate of 5/9 mice. Most (4/5) dead Tg12 mice were strongly positive by EIA (optical density 4.0) and had an average incubation period of 511 days.

Western blots of these 4 Tg12 mice confirmed the presence of proteinase $\mathrm{K}$-resistant $\mathrm{PrP}^{\mathrm{Sc}}$ in the brains (Figure 2). The positive EIA results were obtained from brain homogenates in Tg12 mice; the spleens were negative for $\operatorname{PrP}^{S c}$. For the Tg338 bioassay $(\mathrm{n}=$ 15), brains and spleens were negative by EIA. Four Tg338 mice that died or were euthanized because of intercurrent disease at 254,462, 629, and 657 days postinoculation were negative by EIA. The rest of the Tg338 mice were negative at the study endpoint, 700 days postinoculation.

\section{Conclusions}

The oronasal susceptibility of sheep to the agent of CWD is a major finding in light of its possible effect on risk assessment and understanding possible transmission of CWD to noncervid species in field conditions. Interspecies transmission of TSEs is less likely when the experimental species barrier between hosts is strong (12). One study demonstrated that the CWD agent does not readily transmit to transgenic ovinized mice (13). However, another study reported lifelong replication of $\mathrm{PrP}^{\mathrm{Sc}}$ in the spleen after intracranial inoculation of the CWD agent in Tg338 ovinized mice (14). The finding of extraneuronal $\mathrm{PrP}^{\mathrm{Sc}}$ in 1 sheep 5 years after oral inoculation suggests that sheep are unlikely to develop neurologic disease after natural exposure to the agent of CWD, but they might serve as asymptomatic carriers under the right conditions.

In this study, we used a relatively low dose $(0.1 \mathrm{~g})$ of brain homogenate. These results are intriguing, but they do not assess potential modes of transmission that could occur in the field, such as nose-to-nose contact or

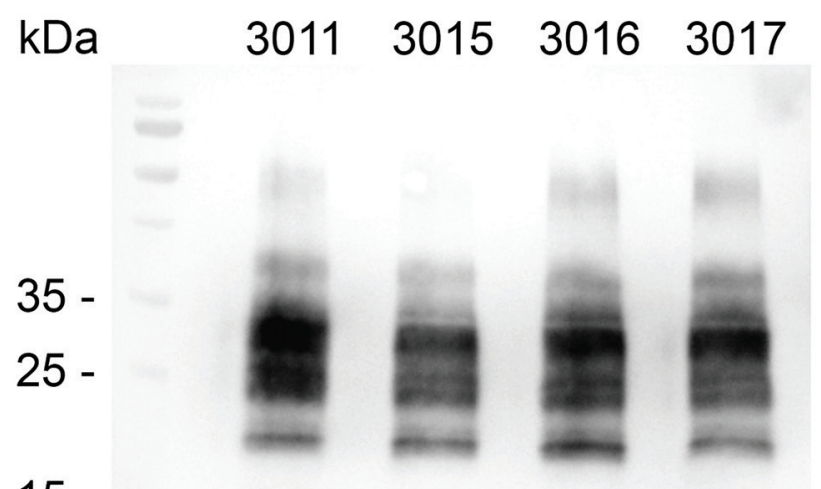
$15-$

Figure 2. Western blot analysis showing proteinase K-resistant misfolded form of the prion protein ( $\mathrm{PrP}^{\mathrm{Sc}}$ ) in brains of $4 \mathrm{Tg} 12$ mice. Mice were intracranially inoculated with a homogenate made from retropharyngeal lymph node of a sheep oronasally inoculated with the agent of chronic wasting disease. Tg12 brain was prepared as a $10 \%$ (wt/vol) homogenate with phosphate-buffered saline. A total of $1 \mathrm{mg}$ of tissue equivalent was treated with proteinase $\mathrm{K}(90 \mu \mathrm{g} / \mathrm{mL})$ before electrophoresis. Immunodetection of $\mathrm{PrP}^{\mathrm{sc}}$ was performed overnight at $4^{\circ} \mathrm{C}$ with monoclonal antibody Sha31 (dilution 1:10,000). Left lane, molecular mass ladder. kDa, kilodaltons. 
environmental contamination. In our ongoing multiyear study, 1 sheep had PrPsc-positive lymphoid tissue but no evidence of neuroinvasion 5 years postinoculation. This time interval is an extremely protracted incubation period. Had we continued this experiment, it is unknown how long the sheep would have remained asymptomatic or whether they would have eventually developed clinical disease. Because $\mathrm{PrP}^{\mathrm{Sc}}$ was detected in lymphoid tissues of the head, the possibility that this sheep might have been shedding infectivity into the environment cannot be ruled out.

Positive bioassay results in Tg12 mice confirm CWD infectivity in the lymph node. Negative results in Tg338 mice could be explained by a donor/host mismatch between the ARQ donor sheep and VRQ expressing mice. Pursuing bioassays in $\mathrm{A}_{136}$-expressing transgenic mice could be more fruitful.

Interspecies transmission events might increase the pathogenicity of an infectious prion on subsequent transmission to other species (15). Thus, exploration of potential new host ranges of this CWD isolate and performing human health risk assessments will provide useful information for this prion.

\section{Acknowledgments}

We thank Quazetta Brown, Rylie Frese, Kevin Hassall, Zoe Lambert, Joe Lesan, Leisa Mandell, and Trudy Tatum for providing excellent technical support; Qingzhong Kong for providing Tg12 mice; and Hubert Laude for providingTg338 mice.

This study was supported by the US Department of Agriculture, Agricultural Research Service. S.J.M. was appointed to the Agricultural Research Service Research Participation Program administered by the Oak Ridge Institute for Science and Education through an interagency agreement between the US Department of Energy and the US Department of Agriculture. The Oak Ridge Institute for Science and Education is managed by Oak Ridge Associated Universities under Department of Energy contract no. DE-SC0014664.

\section{About the Author}

Dr. Cassmann is a research veterinary medical officer at the National Animal Disease Center, Ames, IA. His primary research interests are veterinary pathology, animal prion diseases, interspecies transmission, host ranges, host genetic susceptibility, and diagnostics.

\section{References}

1. Williams ES, Young S. Spongiform encephalopathies in Cervidae. Rev Sci Tech. 1992;11:551-67. https:/ / doi.org/ 10.20506/rst.11.2.611
2. Carlson C, Hopkins C, Nguyen N, Richards B, Walsh D, Walter WD. Chronic wasting disease: status, science, and management support by the US Geological Survey. US Geological Survey; March 2018. Report no. Open-File Report 2017-1138 [cited 2021 Aug 23]. https:// pubs.er.usgs.gov

3. Haley NJ, Hoover EA. Chronic wasting disease of cervids: current knowledge and future perspectives. Annu Rev Anim Biosci. 2015;3:305-25. https://doi.org/10.1146/ annurev-animal-022114-111001

4. Nonno R, Di Bari MA, Pirisinu L, D'Agostino C, Vanni I, Chiappini B, et al. Studies in bank voles reveal strain differences between chronic wasting disease prions from Norway and North America. Proc Natl Acad Sci U S A. 2020;117:31417-26. https:/ / doi.org/10.1073/pnas.2013237117

5. Williams ES. Chronic wasting disease. Vet Pathol. 2005;42:530-49. https://doi.org/10.1354/vp.42-5-530

6. Raymond GJ, Bossers A, Raymond LD, O'Rourke KI, McHolland LE, Bryant PK III, et al. Evidence of a molecular barrier limiting susceptibility of humans, cattle, and sheep to chronic wasting disease. EMBO J. 2000;19:4425-30. https://doi.org/10.1093/emboj/19.17.4425

7. Race RE, Raines A, Baron TG, Miller MW, Jenny A, Williams ES. Comparison of abnormal prion protein glycoform patterns from transmissible spongiform encephalopathy agentinfected deer, elk, sheep, and cattle. J Virol. 2002;76:12365-8. https:// doi.org/10.1128/JVI.76.23.12365-12368.2002

8. Hamir AN, Kunkle RA, Cutlip RC, Miller JM, Williams ES, Richt JA. Transmission of chronic wasting disease of mule deer to Suffolk sheep following intracerebral inoculation. J Vet Diagn Invest. 2006;18:558-65. https:/ / doi.org/10.1177/ 104063870601800606

9. Moore SJ, Smith JD, Greenlee MHW, Nicholson EM, Richt JA, Greenlee JJ. Comparison of two US sheep scrapie isolates supports identification as separate strains. Vet Pathol. 2016;53:1187-96. https:/ / doi.org/10.1177/0300985816629712

10. Kong Q, Huang S, Zou W, Vanegas D, Wang M, Wu D, et al. Chronic wasting disease of elk: transmissibility to humans examined by transgenic mouse models. J Neurosci. 2005; 25:7944-9. https://doi.org/10.1523/JNEUROSCI.2467-05.2005

11. Vilotte JL, Soulier S, Essalmani R, Stinnakre MG, Vaiman D, Lepourry L, et al. Markedly increased susceptibility to natural sheep scrapie of transgenic mice expressing ovine prp. J Virol. 2001;75:5977-84. https:/ / doi.org/10.1128/ JVI.75.13.5977-5984.2001

12. Torres JM, Espinosa JC, Aguilar-Calvo P, Herva ME, Relaño-Ginés A, Villa-Diaz A, et al. Elements modulating the prion species barrier and its passage consequences. PLoS One. 2014;9:e89722. https://doi.org/10.1371/journal.pone.0089722

13. Tamgüney G, Giles K, Bouzamondo-Bernstein E, Bosque PJ, Miller MW, Safar J, et al. Transmission of elk and deer prions to transgenic mice. J Virol. 2006;80:9104-14. https:/ / doi.org/10.1128/JVI.00098-06

14. Béringue V, Herzog L, Jaumain E, Reine F, Sibille P, Le Dur A, et al. Facilitated cross-species transmission of prions in extraneural tissue. Science. 2012;335:472-5. https:/ / doi.org/ 10.1126/science.1215659

15. Espinosa JC, Andréoletti O, Castilla J, Herva ME, Morales M, Alamillo E, et al. Sheep-passaged bovine spongiform encephalopathy agent exhibits altered pathobiological properties in bovine-PrP transgenic mice. J Virol. 2007;81:835-43. https://doi.org/10.1128/JVI.01356-06

Address for correspondence: Justin Greenlee, National Animal Disease Center, Agricultural Research Service, US Department of Agriculture, 1920 Dayton Ave, PO Box 70, Ames, IA 50010, USA; email: justin.greenlee@usda.gov 